\title{
Multiple Fuel Machines Power Economic Dispatch Using Stud Differential Evolution
}

\author{
Naila ${ }^{1}$, Shaikh Saaqib Haroon 2 (1), Shahzad Hassan ${ }^{1, *(1)}$, Salman Amin ${ }^{2}$, Intisar Ali Sajjad ${ }^{2}$ (1), \\ Asad Waqar ${ }^{1}$ (D), Muhammad Aamir ${ }^{1}$, Muneeb Yaqoob ${ }^{1}$ and Imtiaz Alam ${ }^{1}$ (iD \\ 1 Department of Electrical Engineering, Bahria University, Islamabad 44000, Pakistan; \\ 01-244152-038@student.bahria.edu.pk (N.); asadwaqar.buic@bahria.edu.pk (A.W.); \\ muhammadaamir.buic@bahria.edu.pk (M.A.); muneeb.yaqoob@bahria.edu.pk (M.Y.); \\ ialam.buic@bahria.edu.pk (I.A.) \\ 2 Department of Electrical Engineering, University of Engineering \& Technology, Taxila 47050, Pakistan; \\ saaqib.haroon@uettaxila.edu.pk (S.S.H.); salman.amin@uettaxila.edu.pk (S.A.); \\ intisar.ali@uettaxila.edu.pk (I.A.S.) \\ * Correspondence: shassan.buic@bahria.edu.pk
}

Received: 13 April 2018; Accepted: 2 May 2018; Published: 30 May 2018

\begin{abstract}
This paper presents an optimization method for solving the Power Economic Dispatch (PED) problem of thermal generation units with multiple fuels and valve point loadings. The proposed optimizer is a variant of Differential Evolution (DE) characterized as a Stud Differential Evolution (SDE), which has been proposed earlier and implemented on a hydrothermal energy system. In SDE, an operator named Stud Crossover (SC) is introduced in the conventional DE during the trial vector updating process. In SC operator, a best vector gives its optimal information to all other population members through mating. The proposed algorithm's effectiveness to solve Multiple Fuel PED problem, with and without Valve Point Loading Effects (VPLEs), has been validated by testing it on 10 machine multiple fuel standard test systems having $2400 \mathrm{MW}, 2500 \mathrm{MW}, 2600 \mathrm{MW}$, and $2700 \mathrm{MW}$ load demands. The results depict the strength of SDE over various other methods in the literature.
\end{abstract}

Keywords: power economic dispatch; multiple fuel machines; stud differential evolution; stud crossover

\section{Introduction}

The Power Economic Dispatch (PED) is one of the essential steps in operation and planning of a power system. It is an online function and is carried out after every fifteen minutes or on request in control centers. It is a generation allocation problem that is defined as the determination of an optimal generation schedule of machines subjected to the satisfaction of equality and in-equality constraints. PED is non-convex in nature because of Valve Point Loading Effects (VPLEs), Multiple Fuel Options (MFOs), and Prohibited Operating Zones (POZs) [1]. However, most of the time it is addressed as a convex optimization problem solved by conventional techniques; e.g., equal incremental cost criterion, gradient search method [2], Newton's Method (NM), Lambda Iteration Method (LIM), Lagrange Relaxation (LR) [3], Dynamic Programming (DP) [4], and Quadratic Programming (QP) [5], etc. In such techniques, a simple quadratic function represents the machine curve that ignores the practical constraints; e.g., MFOs, POZs, and VPEs. Therefore, these conventional techniques lack the ability of solving highly complex, non-linear, and non-convex optimization problems and thereby fail to find the optimal solution [6].

Thus, for solving such non-convex PED problems, Artificial Intelligence (AI) based approaches were developed, examples include Genetic Algorithm (GA) [7], Particle Swarm Optimization (PSO) [8], 
fuzzy logic [9], Artificial Neural Network (ANN), Simulated Annealing (SA) [10], and Tabu Search (TS) [11], etc. Many other nature inspired algorithms introduced in the literature of economic dispatch include Artificial Bee Colony (ABC) [12,13], Cuckoo Search Algorithm (CSA) [14], Flower Pollination Algorithm (FPA) [15], Bat Algorithm (BAT) [16], Lightning Flash Algorithm (LFA) [17], Ant Lion Optimizer (ALO) [18], Distributed Auction Optimization Algorithm (DAOA) based on the gossip communication mechanism [19], Stud Krill Herd (SKH) [20], Symbiotic Organisms Search (SOS) algorithm [21], and Water Cycle Algorithm (WCA) [22], etc. These techniques are sometimes used in a modified and hybridized manner, such as in Adaptive Cuckoo Search Algorithm (ACSA) [23], Enhanced Lagrangian Artificial Neural Network(ELANN) [24], Modified Symbiotic Organisms Search (MSOS) algorithm [25], Chaotic Bat Algorithm (CBA) [26], New particle swarm optimization with local random search (NPSO_LRS) [27], Improved Genetic Algorithm with Multiplier Updating (IGA_MU) [28], Conventional Genetic Algorithm with Multiplier Updating (CGA_MU) [28], and Particle Swarm Optimization with Gaussian Mutation (PSO_GM) [29] to further optimize search time and results. Evolutionary Algorithms (EAs) are also potential solution methodologies.

Differential Evolution (DE) [30] belongs to the class of EAs. It was first presented by Storn and Price in 1997 [31]. Since it was developed, it has earned the reputation of an efficient global optimization technique for solving non-linear and non-differentiable problems. Some of its advantages include its robustness, simplicity, easy usage, and speed. DE comprises both evolutionary and classic GA strategies. DE is an optimization technique that is most preferred by utility because of its immediate response to practical problems. During the past few years, many variants of DE have also been proposed to solve PED problem such as Self-adaptive DE (SaDE) [32], Improved DE (IDE) [33], Shuffled DE (SDE) [34], hybrid of Continuous Greedy Randomized Adaptive Search Procedure with DE (C-GRASP-DE) [35], hybrid of DE with Particle Swarm Optimization (DEPSO) [1], and many others. DE has a global search capability but it is not always able to search the global optimum solution due to pre-mature convergence. Additionally, its local search ability is also weak.

To cater to all these problems, a variant of DE named Stud Differential Evolution (SDE) has been proposed in this paper. Stud behavior has been proposed and implemented earlier with some evolutionary methods, such as GA [36] and KHA [37]. SDE was proposed by Haroon SS et al. in [38] and was successfully applied for the solution of the emissions constrained hydrothermal energy system problem. However, until now the effectiveness of stud incorporated DE (SDE) has not been examined as a competent solution to convex/non-convex power economic dispatch problems as well as a potential search approach, thereby rendering a research gap in the literature. Another major reason behind the development of SDE is the incompetency of conventional DE in solving complicated multi-modal problems efficiently as it does not always proceed to the global optimum solution. Therefore, a Stud Crossover (SC) operator unlike the conventional crossover operator is introduced that shares the information of an optimal vector with rest of the population vectors and restarts the search through cross-over. The introduced SC operator helps to avoid the entrapment in the local optimum and to find a global optimal solution. SC also empowers the local search ability of the proposed algorithm. Hence with the two said techniques combined, SDE balances the exploitation and exploration altogether, resulting in better performance towards complicated problems.

In this paper, a convex PED (with only MFOs) and a non-convex PED (with both MFOs and VPLEs) have been mapped in SDE. Hence the effectiveness of SDE has been determined by applying it on multiple fuel standard test systems comprising 10 generation-units with power demands of $2700 \mathrm{MW}, 2600 \mathrm{MW}, 2500 \mathrm{MW}$, and $2400 \mathrm{MW}$.

\section{Problem Formulation}

Mathematically, the PED problem is usually modeled by its objective function and constraints related to generating units. The objective function of PED is to minimize the total fuel cost of all power generation units while satisfying the power balance constraint and generation capacity constraint of the power system. 


\subsection{Objective Function}

The objective of the PED problem is to minimize the overall power generation cost. Equation (1) is a mathematical representation of the objective function of PED.

$$
\min F_{T}=\sum_{i=1}^{N} F_{i}\left(P_{G_{i}}\right)
$$

where, $F_{T}$ is the overall power generation cost to be minimized, $F_{i}\left(P_{G_{i}}\right)$ is the fuel cost associated with $i$ th unit, $P_{G_{i}}$ is the power generated from $i$ th unit and $N$ is the number of units. The fuel cost equation of a simple PED problem, for an ideal power system, is a quadratic function and is given in Equation (2).

$$
F_{i}\left(P_{G_{i}}\right)=a_{i}+b_{i} P_{G_{i}}+c_{i} P_{G_{i}}^{2}
$$

Here, $a_{i}, b_{i}$ and $c_{i}$ are the fuel cost coefficients of the $i$ th generator. The fuel cost curve for above quadratic fuel cost equation has been shown in Figure 1. It depicts the fuel cost characteristics of a simple economic dispatch problem.

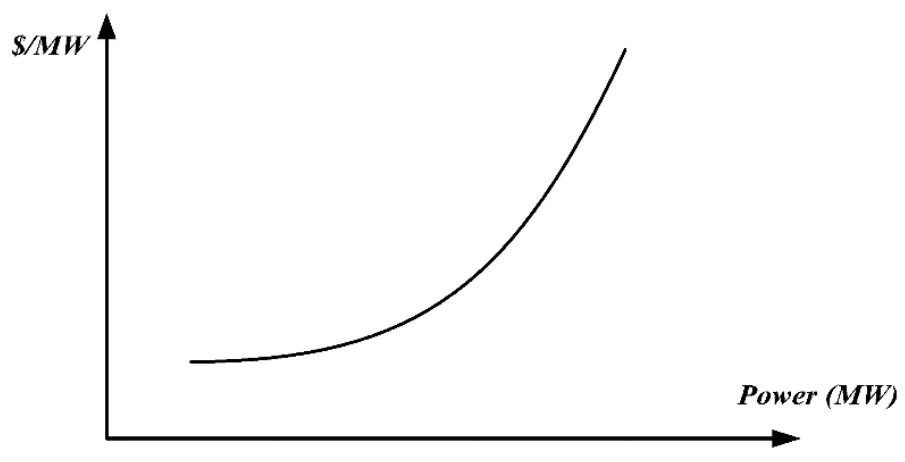

Figure 1. Fuel cost curve for simple Power Economic Dispatch (PED) problem.

\subsection{Constraints}

The following are the constraints that are supposed to be satisfied while achieving the objective function of PED.

\subsubsection{Equality Constraint}

The sum of power generated from all units is required to be equal to the total power demand as represented through Equation (3).

$$
\sum_{i=1}^{N} P_{G_{i}}=P_{d}
$$

\subsubsection{In-Equality Constraint}

The value of power generated by each unit should lie inside the maximum and minimum power generation limit of that unit. Equation (4) presents this constraint of generation capacity.

$$
P_{G_{i}}^{\min } \leq P_{G_{i}} \leq P_{G_{i}}^{\max }
$$

where, $P_{D}$ is the total power demand, $P_{G_{i}}$ is the power generated by ith unit and $P_{G_{i}}^{\min }$ and $P_{G_{i}}^{\max }$ are the minimum and maximum power limits from $i$ th generation unit respectively. 


\subsection{Fuel Cost Equations}

Practically, the objective function of PED problem is non-differentiable and non-convex in nature because of VPLEs and MFOs. Therefore, the objective function of PED is modeled in terms of following fuel cost equations for practical power systems.

2.3.1. Power Economic Dispatch considering Valve Point Loading Effects Only

The fuel cost equation for a PED problem with only VPLEs is as under,

$$
F_{i}\left(P_{G_{i}}\right)=a_{i}+b_{i} P_{G_{i}}+c_{i} P_{G_{i}}^{2}+\left|e_{i} \sin \left(f_{i}\left(P_{G_{i}}^{\min }-P_{G_{i}}\right)\right)\right|
$$

The fuel cost curve for such type of PED has been presented in Figure 2.

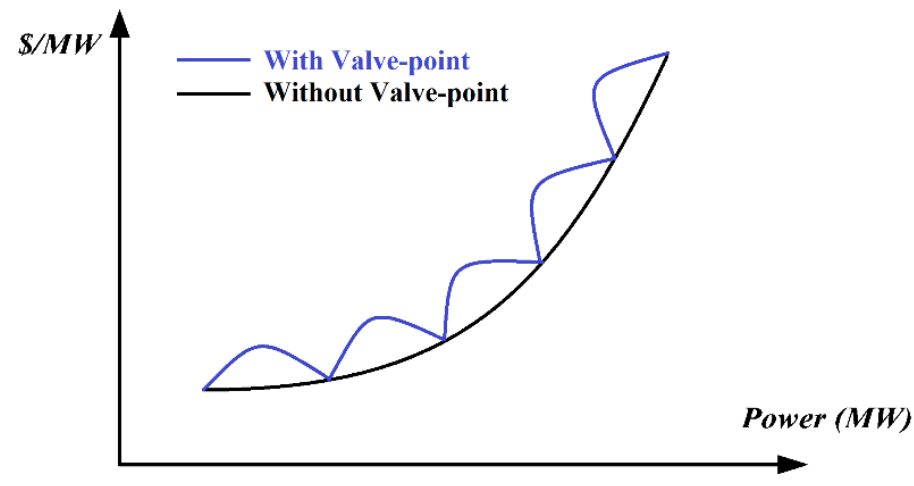

Figure 2. Fuel cost curve for PED problem with Valve Point Loading Effects (VPLEs).

\subsubsection{Power Economic Dispatch Considering Multiple Fuel Options Only}

The fuel cost equation for a PED problem with only MFOs, is as under in Equation (6).

$$
F_{i}\left(P_{G_{i}}\right)=\left\{\begin{array}{ccc}
a_{i 1}+b_{i 1} P_{G_{i}}+c_{i 1} P_{G_{i}{ }^{\prime}}^{2} & \text { fuel } 1, & P_{G_{i}}^{\min } \leq P_{G_{i}} \leq P_{i 1} \\
a_{i 2}+b_{i 2} P_{G_{i}}+c_{i 2} P_{G_{i}}^{\prime} & \text { fuel } 2, & P_{i 1} \leq P_{G_{i}} \leq P_{i 2} \\
& , & \\
& , & \\
& , & \\
a_{i k}+b_{i k} P_{G_{i}}+c_{i k} P_{G_{i}}^{2}, & \text { fuel } k, & P_{i k-1} \leq P_{G_{i}} \leq P_{G_{i}}^{\max }
\end{array}\right.
$$

where, $P_{i k}^{\min }$ and $P_{i k}^{\max }$ are the minimum and maximum power generations from $i$ th unit consuming $k$ th fuel respectively. $a_{i k}, b_{i k}$ and $c_{i k}$ are the cost coefficients of the $i$ th generating unit consuming $k$ th fuel. Figure 3 represents the fuel cost characteristics of a PED problem that considers only MFOs for generating units. 


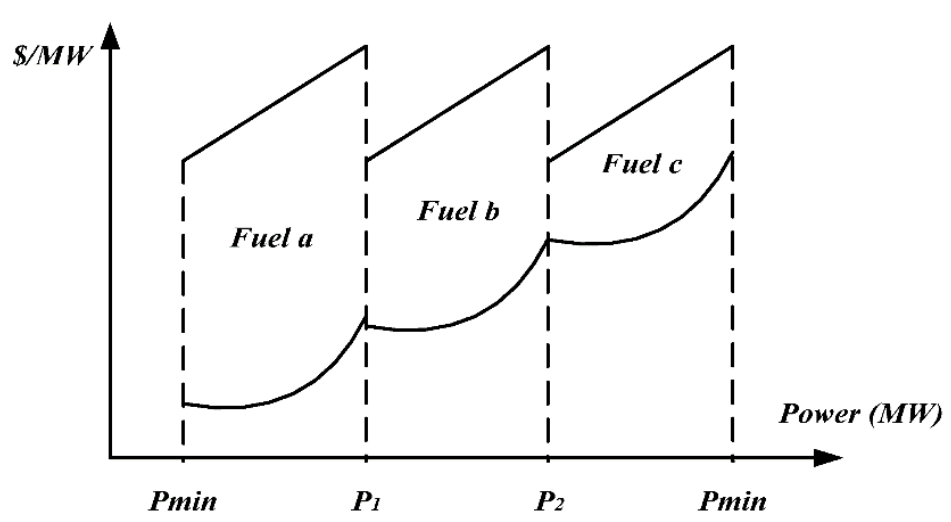

Figure 3. Fuel cost curve for PED problem with Multiple Fuel Options (MFOs).

2.3.3. Power Economic Dispatch Considering Multiple Fuel Options and Valve Point Loading Effects Together

The fuel cost equation for a PED problem modeling both MFOs and VPLEs, is as under in Equation (7).

$$
F_{i}\left(P_{G_{i}}\right)=\left\{\begin{array}{c}
a_{i 1}+b_{i 1} P_{G_{i}}+c_{i 1} P_{G_{i}}^{2}+\left|e_{i 1} \sin \left(f_{i 1}\left(P_{G_{i}}^{\min }-P_{G_{i}}\right)\right)\right| \\
\text { fuel } 1, \quad P_{G_{i}}^{\min } \leq P_{G_{i}} \leq P_{i 1} \\
a_{i 2}+b_{i 2} P_{G_{i}}+c_{i 2} P_{G_{i}}^{2}+\left|e_{i 2} \sin \left(f_{i 2}\left(P_{G_{i}}^{\min }-P_{G_{i}}\right)\right)\right| \\
\text { fuel } 2, \quad P_{i 1} \leq P_{G_{i}} \leq P_{i 2} \\
, \\
, \\
, \\
, \\
a_{i k}+b_{i k} P_{G_{i}}+c_{i k} P_{G_{i}}^{2}+\left|e_{i k} \sin \left(f_{i k}\left(P_{G_{i}}^{\min }-P_{G_{i}}\right)\right)\right| \\
\text { fuel k, } P_{i k-1} \leq P_{G_{i}} \leq P_{G_{i}}^{\max }
\end{array}\right.
$$

\section{Differential Evolution (DE)}

DE is a population-based algorithm in which mutation, crossover, and selection are its essential components. It uses mutation as a main search strategy and employs the selection operator to direct the search towards the potential solution region. It builds two arrays: a primary array and a secondary array. Both arrays hold NP number of potential solutions and each solution contains D number of parameters. These solutions are real valued vectors. In short, there is $N P$ number of $\mathrm{D}$-dimensional vectors. All vectors collectively are called a population. The first array comprises of the current vector population and the second array collects vectors that are selected for next generation.

Following is the stepwise description of DE.

Step 1: Randomly initialize the initial population $P_{i}^{G}$ (target vectors) of $N P$ size and of $D$ dimensions, in a feasible range.

$$
\begin{gathered}
P S^{G}=\left[P_{1}^{G}, P_{2}^{G}, \ldots \ldots \ldots . . P_{N p}^{G}\right] \\
P_{i}^{G}=\left[P_{1, i}^{G}, P_{2, i}^{G}, \ldots \ldots \ldots . . P_{D, i}^{G}\right] \quad i=1,2, \ldots \ldots \ldots . ., N_{p}
\end{gathered}
$$

where, $P_{i}^{G}$ is the $i$ th potential solution and $D$ is the $D$ th generating unit.

As the population is defined within permissible range,

$$
P_{j, i}^{0}=P_{j, i}^{\min }+\delta_{j} *\left(P_{j, i}^{\max }-P_{j, i}^{\min }\right)
$$


where, $i=1,2, \ldots \ldots \ldots \ldots, N_{p} j=1,2, \ldots \ldots \ldots . ., D$

In Equation (10), $D$ is the total number of decision parameters, $P_{j, i}^{\min }$ and $P_{j, i}^{\max }$ are the lower and upper limits of the $j$ th parameter respectively and $\delta_{j}$ is a random number generated in a range $0-1$ which is new for every new value of $j$.

Step 2: Calculate the fitness value for all generated target vectors.

Step 3: Generate the mutant vector $V_{i}^{G}$ by perturbing a randomly selected vector $P_{k}^{G}$ with the difference of two other randomly selected vectors $P_{l}^{G}$ and $P_{m}^{G}$ according to Rand $/ 1 /$ bin mutation strategy.

Step 4: Generate the trial vectors $\left(U_{i}^{G}\right)$ through crossover by randomly recombining the parameters of target vectors $\left(P_{i}^{G}\right)$ and mutant vectors $\left(V_{i}^{G}\right)$.

$$
U_{j, i}^{G}=\left\{\begin{array}{cl}
V_{j, i}^{G} & \text { if }\left(\rho_{j}<C R\right) \text { or } j=D \\
P_{j, i}^{G} & \text { Otherwise }
\end{array}\right.
$$

Step 5: Calculate the fitness value for each trial vector generated in step 4.

Step 6: Perform 1-1 comparison between target vectors and trial vectors and select the vectors with improved fitness value for new offspring.

$$
P_{i}^{G+1}= \begin{cases}U_{i}^{G} & \text { if } f\left(U_{i}^{G}\right)>f\left(P_{i}^{G}\right) \\ P_{i}^{G} & \text { Otherwise }\end{cases}
$$

Step 7: Check whether desired fitness value is attained or maximum number of generations is achieved, if yes then stop this optimization process, otherwise go back to step 3.

\section{Stud Differential Evolution (SDE)}

Because the conventional DE method suffers from premature convergence, it cannot always find the optimal solution, especially for the systems with turbulent search space. Therefore, in this research work, an improved strategy of crossover known as SC operator has been introduced in conventional DE in order to improve its performance in solving the PED problem of thermal units with MFOs and VPLEs. This improved version of DE called SDE is inspired by Stud GA. In SDE, to begin with, the conventional DE is implemented to reduce the research space to the strategic area and afterwards the SC operator is applied. SC operator is the heart of SDE and is utilized to mate all population vectors with only the best vector or the most optimal vector called stud. It results in the generation of better quality solutions instead of not so good solutions for upcoming offspring.

In SDE, the trial vectors $\left(U_{i}^{G}\right)$ are generated for all potential solutions (vectors) of population by recombining the parameters of best vector $P_{b e s t}^{G}$ (instead of target vectors as in conventional DE) from the current generation $\mathrm{G}$ and mutant vectors $\left(V_{i}^{G}\right)$. The $\mathrm{SC}$ operator is represented by the following mathematical expression.

$$
U_{j, i}^{G}=\left\{\begin{array}{l}
V_{j, i}^{G} \quad \text { if }\left(\rho_{j}<C R\right) \text { or } j=D \\
P_{\text {best }}^{G} \quad \text { Otherwise }
\end{array}\right.
$$

The mainframe of SDE operator and SC has been given in Algorithms 1 and 2 respectively. Figure 4 depicts the flowchart of the proposed optimization method.

As we can see in Algorithm 1, to begin with, the optimal vector (stud) is selected as first parent to mate with another parent vector to create a novel child/trial vector through crossover operator. It must be ensured that stud should not be selected as second parent. Then the quality of a generated child vector is determined by fitness function. 


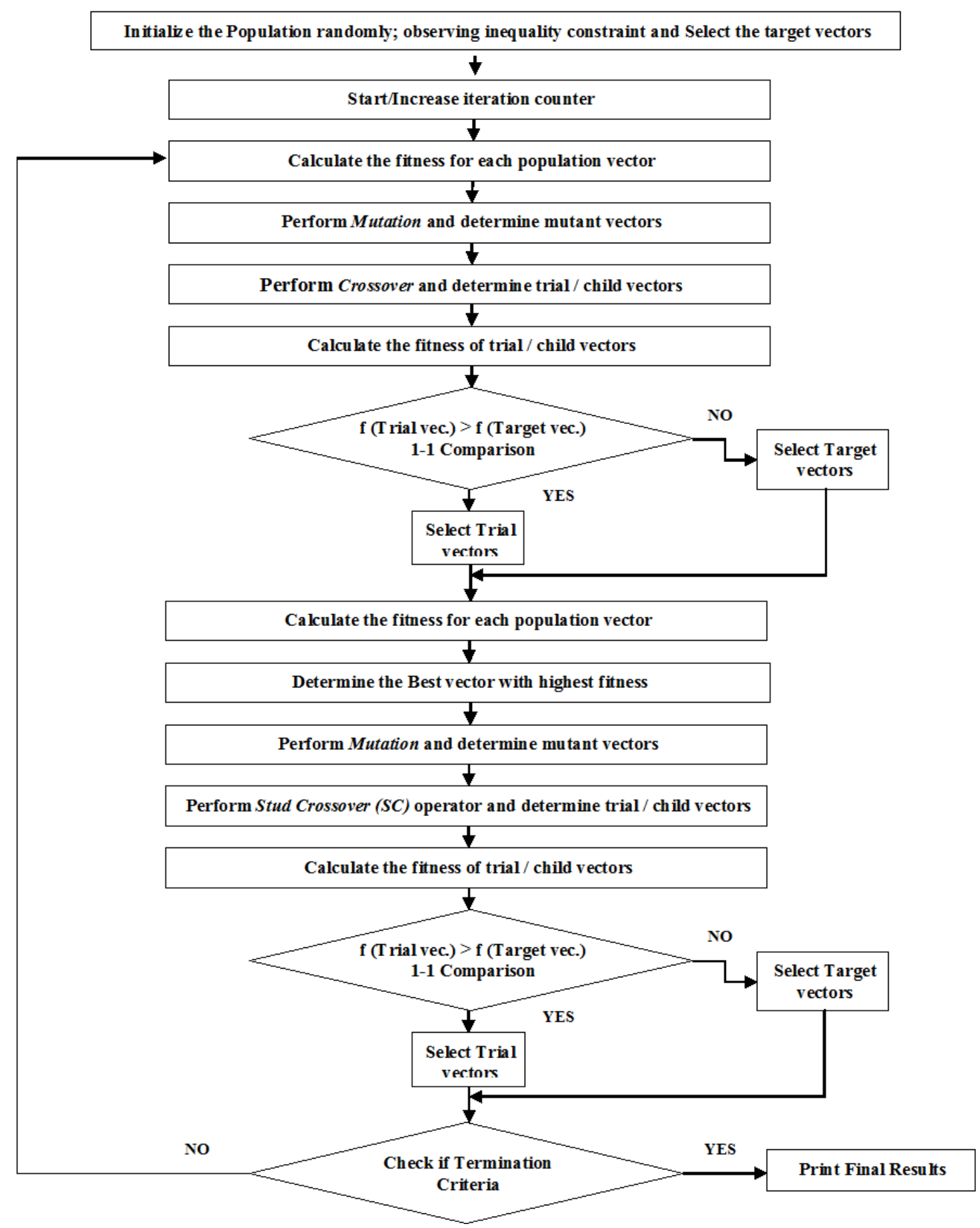

Figure 4. Flow chart of proposed Stud Differential Equation (SDE). 

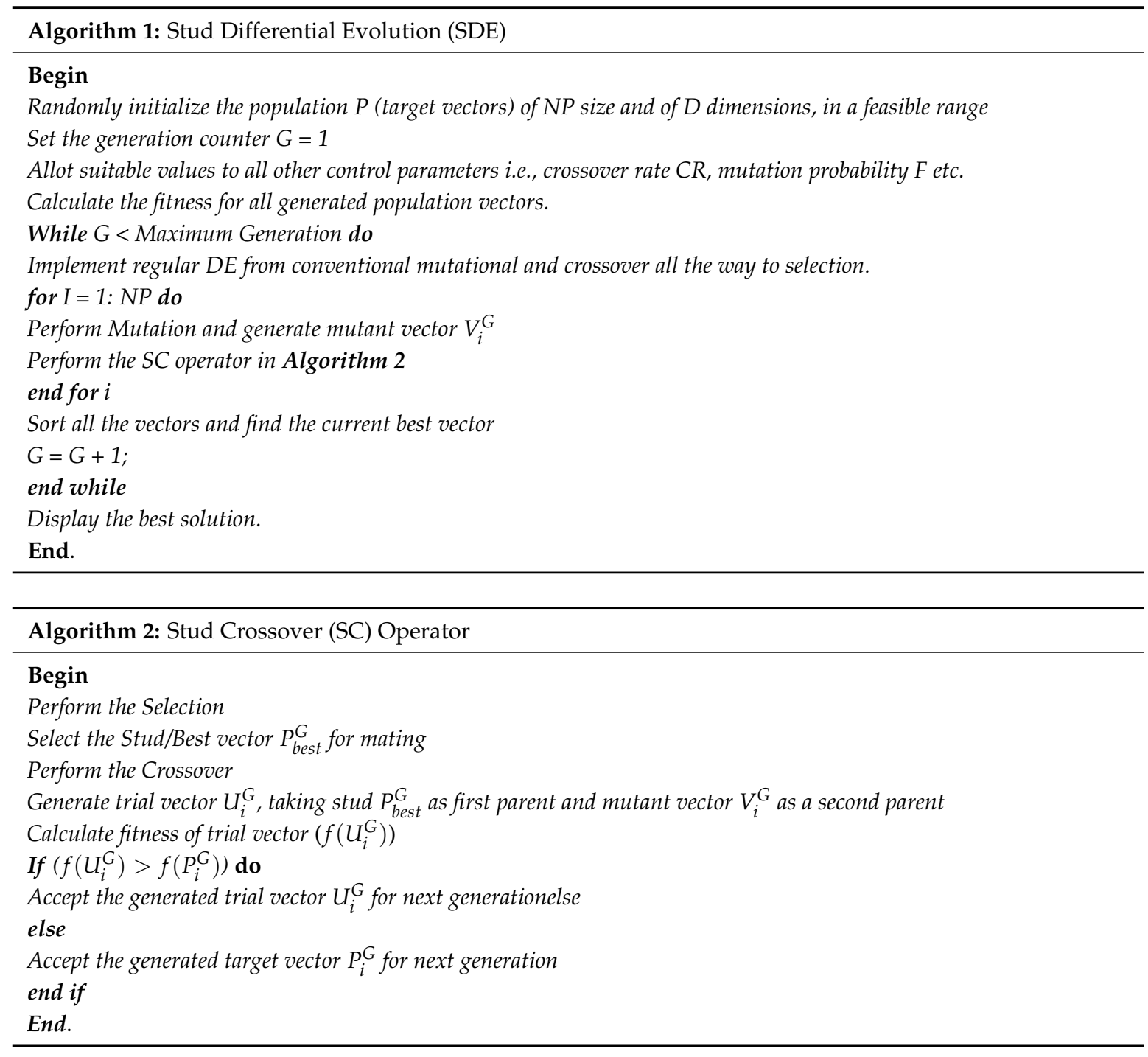

\section{Simulation Results}

The proposed SDE is implemented in a Visual C++ environment on various IEEE standard test systems. For computer implementation of SDE, a Pentium IV computer with 1 GB of RAM and $2.0 \mathrm{GHz}$ processor speed is used. Software used is Microsoft Visual C++ version 8.0. In order to validate the effectiveness of the proposed SDE, it has been tested on two 10-machine multiple fuel test systems. In one system, VPLEs has been considered (a 10-machine system with non-convex cost function) while it has been neglected in the other one (a system with convex cost function). Further, four case studies for various load demands of $2400 \mathrm{MW}, 2500 \mathrm{MW}, 2600 \mathrm{MW}$, and $2700 \mathrm{MW}$ have been conducted for each above mentioned system. The inputs to the proposed SDE are cost coefficients, power generation limits of each unit and demand power while the outputs of the proposed algorithm are power generation values from each unit, computation time, and type of fuel of each generating unit.

Parameter Selection: There are three main parameters in SDE that need to be predetermined; the population size $(\mathrm{NP})$, mutation factor $(\mathrm{F})$ and crossover rate $(\mathrm{CR})$.

\subsection{System 1: 10 Machine Multiple Fuel Convex PED (without Valve Point Loading Effects)}

This system consists of 10 generating units, considering only MFOs while ignoring the VPLEs. The simulations for this system have been conducted for four different power demands of $2700 \mathrm{MW}$, $2600 \mathrm{MW}, 2500 \mathrm{MW}$, and $2400 \mathrm{MW}$. The input data for the system has been taken from [39]. The selected parameters for this system are: Population size $=100$, No. of iterations $=200$, Crossover rate 
$(C R)=0.6$, Mutation factor $(M F)=0.5$ and the results are presented after 30 repeated trials. Tables 1-4 indicate the power generation schedule and generation cost obtained by the proposed SDE for the load demands of $2700 \mathrm{MW}, 2600 \mathrm{MW}, 2500 \mathrm{MW}$, and $2400 \mathrm{MW}$ respectively. In Table 1, the effectiveness of SDE in solving convex PED problem, for the power demand of $2700 \mathrm{MW}$, has been validated by comparing its results with other optimizers in the literature such as Modified Shuffled Frog Leaping Algorithm (MSFLA) [40], Modified Hopfield Neural Network (MHNN) [41], Self-adaptive Differential Evolution (SaDE) [32], and Improved Evolutionary Programming (IEP) [42]. Similarly, Table 2 shows the simulation result of SDE for the power demand of $2600 \mathrm{MW}$, compared with Hopfield Lagrange Network (HLN) [43], Lamda-Iteration (LI) [43], and SaDE [32]. Table 3 depicts the cost comparison of the proposed method to Modified Particle Swarm Optimization (MPSO) [44], Enhanced Augmented Lagrange Hopfield Network (EALHN) [45], and Artificial Immune System (AIS) [46] against the power demand of $2500 \mathrm{MW}$. Table 4 indicates the comparison of SDE simulation results among MHNN [41], AIS [46], EALHN [45], and MPSO [44] for the power demand of $2400 \mathrm{MW.}$

Table 1. Cost comparison among various methodologies for System $1, \mathrm{P}_{\mathrm{d}}=2700 \mathrm{MW}$.

\begin{tabular}{ccccccc}
\hline \multirow{2}{*}{ Unit No. } & \multirow{2}{*}{ Fuel Types } & \multicolumn{5}{c}{ Methods } \\
\cline { 2 - 6 } & & MSFLA & MHNN & SaDE & IEP & SDE \\
\hline P1 & 2 & 226.57 & 224.50 & 218.94 & 219.54 & 218.249988 \\
P2 & 1 & 215.35 & 215.00 & 212.72 & 211.44 & 211.662614 \\
P3 & 1 & 291.35 & 291.80 & 282.63 & 279.68 & 280.722785 \\
P4 & 3 & 242.24 & 242.20 & 239.77 & 240.32 & 239.631553 \\
P5 & 1 & 293.02 & 293.30 & 277.46 & 276.53 & 278.497228 \\
P6 & 3 & 242.24 & 242.20 & 240.18 & 239.87 & 239.631562 \\
P7 & 1 & 302.57 & 303.10 & 287.29 & 289.00 & 288.584580 \\
P8 & 3 & 242.24 & 242.20 & 239.91 & 241.31 & 239.631491 \\
P9 & 3 & 355.50 & 355.70 & 426.09 & 425.14 & 428.521600 \\
P10 & 1 & 288.91 & 289.50 & 275.01 & 277.17 & 274.866600 \\
\hline \multicolumn{2}{c}{ Power Generated } & 2700.00 & 2699.70 & 2700.00 & 2700.00 & 2700.00 \\
\multicolumn{2}{c}{ Total Cost } & 626.25 & 626.12 & 623.92 & 623.85 & 623.809154 \\
\hline
\end{tabular}

Table 2. Cost comparison among various methodologies for System 1, $\mathrm{P}_{\mathrm{d}}=2600 \mathrm{MW}$.

\begin{tabular}{cccccc}
\hline \multirow{2}{*}{ Unit No. } & Fuel Used & \multicolumn{4}{c}{ Methods } \\
\cline { 3 - 6 } & & HLN & LI & SaDE & SDE \\
\hline P1 & 2 & 209.7882 & 209.788 & 218.23 & 216.544182 \\
P2 & 1 & 207.9078 & 207.9078 & 211.71 & 210.905752 \\
P3 & 1 & 269.9145 & 269.9146 & 276.77 & 278.544078 \\
P4 & 3 & 236.9782 & 236.9782 & 239.37 & 239.096668 \\
P5 & 1 & 263.7247 & 263.7247 & 275.65 & 275.519445 \\
P6 & 3 & 236.9782 & 236.9782 & 240.18 & 239.096668 \\
P7 & 1 & 274.359 & 274.3591 & 285.99 & 285.717009 \\
P8 & 3 & 236.9782 & 236.9782 & 238.16 & 239.096669 \\
P9 & 1 & 402.7945 & 402.7945 & 341.90 & 343.493387 \\
P10 & 1 & 260.5768 & 260.5767 & 272.04 & 271.986142 \\
\hline Power Generated & 2600.00 & 2600.00 & 2600.00 & 2600.00 \\
\multicolumn{2}{c}{ Total Cost } & 574.74 & 574.74 & 574.54 & 574.380823 \\
\hline
\end{tabular}


Table 3. Cost comparison among various methodologies for System $1, \mathrm{P}_{\mathrm{d}}=2500 \mathrm{MW}$.

\begin{tabular}{cccccc}
\hline \multirow{2}{*}{ Unit No. } & Fuel Used & \multicolumn{4}{c}{ Methods } \\
\cline { 3 - 6 } & & MPSO & EALHN & AIS & SDE \\
\hline P1 & 2 & 206.5 & 206.5188 & 205.88 & 206.519016 \\
P2 & 1 & 206.5 & 206.4573 & 206.33 & 206.457317 \\
P3 & 1 & 265.7 & 265.7392 & 266.48 & 265.739085 \\
P4 & 3 & 236.0 & 235.9531 & 235.79 & 235.953146 \\
P5 & 1 & 258.0 & 258.0178 & 256.87 & 258.017644 \\
P6 & 3 & 236.0 & 235.9531 & 236.65 & 235.953163 \\
P7 & 1 & 268.9 & 268.8636 & 269.2 & 268.863542 \\
P8 & 3 & 235.9 & 235.9531 & 235.51 & 235.953149 \\
P9 & 1 & 331.5 & 331.4876 & 332.23 & 331.487723 \\
P10 & 1 & 255.1 & 255.0564 & 255.02 & 255.056214 \\
\hline Power Generated & 2500.00 & 2500.00 & 2500.00 & 2500.00 \\
\multicolumn{2}{c}{ Total Cost } & 526.239 & 526.239 & 526.240 & 526.238760 \\
\hline
\end{tabular}

Table 4. Cost comparison among various methodologies for System 1, $\mathrm{P}_{\mathrm{d}}=2400 \mathrm{MW}$.

\begin{tabular}{ccccccc}
\hline \multirow{2}{*}{ Unit No. } & \multirow{2}{*}{ Fuel Used } & \multicolumn{5}{c}{ Methods } \\
\cline { 3 - 7 } & & MHNN & AIS & EALHN & MPSO & SDE \\
\hline P1 & 1 & 192.7 & 189.683 & 189.7397 & 189.7 & 189.740527 \\
P2 & 1 & 203.8 & 202.40 & 202.3427 & 202.3 & 202.342694 \\
P3 & 1 & 259.1 & 253.814 & 253.8954 & 253.9 & 253.895318 \\
P4 & 3 & 195.1 & 233.019 & 233.0456 & 233.0 & 233.045560 \\
P5 & 1 & 248.7 & 241.94 & 241.8299 & 241.8 & 241.829619 \\
P6 & 3 & 234.2 & 233.063 & 233.0456 & 233.0 & 233.045548 \\
P7 & 1 & 260.3 & 253.374 & 253.2752 & 253.3 & 253.275055 \\
P8 & 3 & 234.5 & 232.851 & 233.0456 & 233.0 & 233.045563 \\
P9 & 1 & 324.7 & 320.452 & 320.3831 & 320.4 & 320.383139 \\
P10 & 1 & 246.8 & 239.404 & 239.3973 & 339.4 & 239.396978 \\
\hline \multicolumn{2}{c}{ Power Generated } & 2399.8 & 2400.00 & 2399.80 & 2400 & 2400 \\
\multicolumn{2}{c}{ Total Cost } & 487.87 & 481.723 & 481.72300 & 481.723 & 481.722624 \\
\hline
\end{tabular}

The best generation costs and computational times of the proposed method is compared to those from HNN [41], SaDE [32], IEP [42], ELANN [24], EALHN [45], MPSO [44], RCGA [47], DE [48], and LI [43] for all power demands of $2400 \mathrm{MW}, 2500 \mathrm{MW}, 2600 \mathrm{MW}$, and $2700 \mathrm{MW}$, as shown in Table 5 (i, ii, iii, iv) respectively. It is evident from the table that the total fuel cost obtained by the proposed SDE is less than all other algorithms except the LI for $2400 \mathrm{MW}$, HNN for $2500 \mathrm{MW}$ and $2600 \mathrm{MW}$ cases. However, computational time of the proposed SDE is shorter than LI and HNN for all cases. Additionally, $\mathrm{HNN}$ fails to meet the power balance constraint in all cases. As for the $2700 \mathrm{MW}$ case, the simulation results of SDE are better than all mentioned algorithms. The convergence characteristics of the proposed method in solving the convex PED problem (with MFOs and without VPLEs), for 2600 MW, 2500 MW, and 2400 MW load demands, are shown in Figure 4 while those for 2700 MW load demand are presented in Figure 5. 
Table 5. Comprehensive comparison of total fuel cost and computation time for system 1 (without valve point loading effects), $\mathrm{P}_{\mathrm{d}}=2400 \mathrm{MW}, 2500 \mathrm{MW}, 2600 \mathrm{MW}$ and $2700 \mathrm{MW}$.

\begin{tabular}{|c|c|c|c|c|c|c|c|}
\hline \multicolumn{4}{|c|}{ (i) } & \multicolumn{4}{|c|}{ (ii) } \\
\hline \multicolumn{4}{|c|}{$2400 \mathrm{MW}$} & \multicolumn{4}{|c|}{$2500 \mathrm{MW}$} \\
\hline Methods & Total Power & Min. Cost & $\mathrm{CT}$ & Methods & Total Power & Min. Cost & $\mathrm{CT}$ \\
\hline HNN [41] & 2399.80 & 481.8700 & $\sim 60$ & IEP [42] & 2500.00 & 526.4000 & NR \\
\hline SaDE [32] & 2400.00 & 481.8628 & NR & SaDE [32] & 2500.00 & 526.3232 & NR \\
\hline IEP [42] & 2400.00 & 481.7790 & NR & ELANN [24] & 2500.00 & 526.2700 & 12.25 \\
\hline ELANN [24] & 2400.00 & 481.7400 & 11.53 & DE [48] & 2500.00 & 526.2390 & NR \\
\hline EALHN [45] & 2400.00 & 481.7230 & 0.008 & EALHN [45] & 2500.00 & 526.2390 & 0.006 \\
\hline MPSO [44] & 2400.00 & 481.7230 & NR & LI [43] & 2500.00 & 526.2390 & 2.508 \\
\hline RCGA [47] & 2400.00 & 481.7230 & 49.92 & RCGA [47] & 2500.00 & 526.2390 & 49.92 \\
\hline $\mathrm{DE}[48]$ & 2400.00 & 481.7230 & NR & MPSO [44] & 2500.00 & 526.2390 & NR \\
\hline LI [43] & 2399.99 & 481.7217 & 7.84 & HNN [41] & 2499.80 & 526.1300 & $\sim 60$ \\
\hline SDE & 2400.00 & 481.7226 & 2.50 & SDE & 2500.00 & 526.2387 & 2.43 \\
\hline \multicolumn{4}{|c|}{ (iii) } & \multicolumn{4}{|c|}{ (iv) } \\
\hline \multicolumn{4}{|c|}{$2600 \mathrm{MW}$} & \multicolumn{4}{|c|}{$2700 \mathrm{MW}$} \\
\hline Methods & Total Power & Min. Cost & $\mathrm{CT}$ & Methods & Total Power & Min. Cost & CT \\
\hline LI [43] & 2600.00 & 574.7412 & 6.871 & HNN [41] & 2599.80 & 626.1200 & $\sim 60$ \\
\hline HLN [43] & 2600.00 & 574.7413 & 0.152 & SaDE [32] & 2700.00 & 623.9225 & NR \\
\hline SaDE [32] & 2600.00 & 574.5380 & NR & ELANN [24] & 2700.00 & 623.8800 & 21.36 \\
\hline IEP [42] & 2600.00 & 574.4730 & NR & IEP [42] & 2700.00 & 623.8510 & NR \\
\hline ELANN [24] & 2600.00 & 574.4100 & $\sim 9.99$ & RCGA [47] & 2700.00 & 623.8092 & 44.56 \\
\hline RCGA [47] & 2600.00 & 574.3960 & 33.57 & DE [48] & 2700.00 & 623.8090 & NR \\
\hline $\mathrm{DE}[48]$ & 2600.00 & 574.3810 & NR & LI [43] & 2699.99 & 623.8089 & 6.221 \\
\hline EALHN [45] & 2600.00 & 574.3810 & 0.005 & MPSO [44] & 2700.00 & 623.8090 & NR \\
\hline MPSO [44] & 2600.00 & 574.3810 & NR & CGA-MU [28] & 2700.00 & 623.8095 & 19.42 \\
\hline HNN [41] & 2599.80 & 574.2600 & $\sim 60$ & IGA-MU [28] & 2700.00 & 623.8093 & 5.27 \\
\hline SDE & 2600.00 & 574.3808 & 2.04 & SDE & 2700.00 & 623.8092 & 2.2 \\
\hline
\end{tabular}

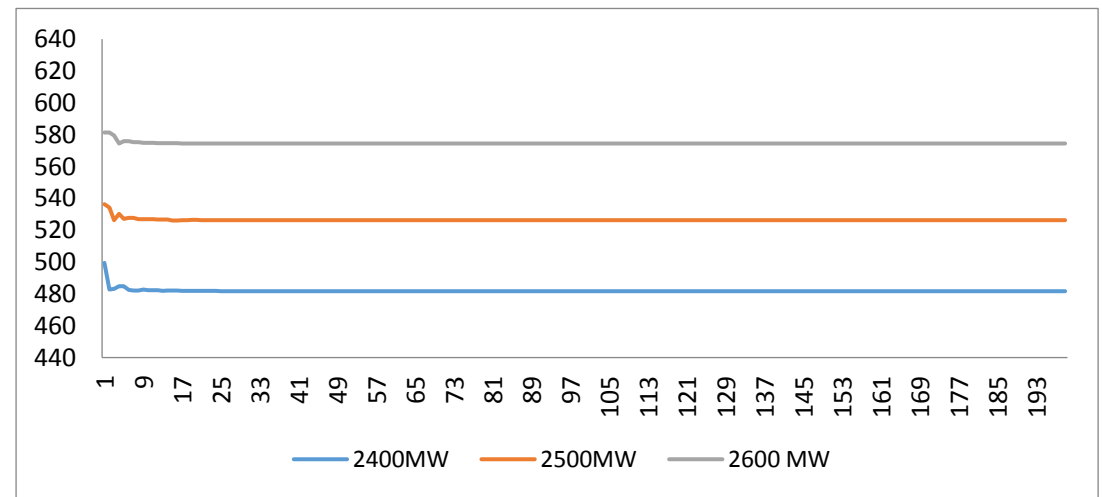

Figure 5. Convergence-characteristics of SBE algorithm for system 1 (without valve point loading effects), $P_{d}=2400 \mathrm{MW}, 2500 \mathrm{MW}, 2600 \mathrm{MW}$.

\subsection{System 2: 10 Machine Multiple Fuel Non-Convex PED (with Valve Point Loading Effects)}

This system considers both MFOs and the VPLEs. The simulations for this system have also been conducted for $2700 \mathrm{MW}, 2600 \mathrm{MW}, 2500 \mathrm{MW}$ and $2400 \mathrm{MW}$ power demands. The selected parameters for this system are: Population size $=200$, No. of iterations $=800$, Crossover rate $(C R)=0.6$, Mutation factor $(\mathrm{MF})=0.5$ and the results are presented after 30 trials. Table 6 shows the results obtained from the proposed SDE in solving non-convex PED problem for the $2700 \mathrm{MW}$ power demand and are compared to other optimizers in literature such as Improved Genetic Algorithm with Multiplier Updating (IGA_MU) [28], Modified Shuffled Frog Leaping Algorithm (MSFLA) [40], Particle Swarm Optimization (PSO) [49], conventional DE [49], Real-coded Genetic Algorithm (RGA) [49], New Particle 
Swarm Optimization with Local Random Search (NPSO-LRS) [50], Back-tracking Search Algorithm (BSA) [51], Cuckoo Search Algorithm with Cauchy distribution (CSA-Cauchy) [52] and BAT [16]. Table 7 shows the simulation results of SDE for the power demand of $2600 \mathrm{MW}$ and are compared with conventional PSO [49], RGA [49], DE [49], MSFLA [40], Global-best Harmony Search (GHS) [40], BAT [16], SaDE [32]. In Table 8, SDE simulation results have been compared with DE [49], RGA [49], PSO [49] and Adaptive Simulated Annealing (ASA) [53] for 2500 MW load demand. For 2400 MW load demand, SDE outperforms all mentioned algorithms same as all other power demands $(2700 \mathrm{MW}$, $2600 \mathrm{MW}$ and $2500 \mathrm{MW}$ ), as illustrated by Table 9. Table 10 shows optimal solutions for different values of Crossover ratio (CR).

For the power demand of $2700 \mathrm{MW}$, the comparison of the proposed SDE with various optimization techniques in literature been performed in Table 10 comprising maximum, average and minimum generation costs, standard deviation and computational time of the reported algorithms. From all above result comparisons, it is clearly found that the proposed SDE provides high quality results compared to all other methodologies. The convergence characteristics of the proposed optimizer while solving the non-convex PED problem (with both MFOs and VPLEs) for $2600 \mathrm{MW}, 2500 \mathrm{MW}$ and 2400 MW load demands, are shown in Figure 6 while those for 2700 MW load demand are presented in Figure 7. It is also clear from the figures that SDE can converge to high quality solutions within reasonable time. It is robust and can converge to optimal solution at early iterations. The distribution of power-generation costs of the proposed SDE, for $2700 \mathrm{MW}$ power demand during 30 repeated runs, has been illustrated in Figure 8. It is evident from the figure that the optimal generation cost has been achieved at 19 th run by SDE. Figure 9 shows the cost distribution around 30 runs for system 2 . Table 11 shows the comparison of the results obtained by SDE with other approaches of literature for all the power demands and Table 12 presents the summary of simulation results achieved by the proposed SDE while solving both convex and non-convex PED problems with four power demands of $2700 \mathrm{MW}$, $2600 \mathrm{MW}, 2500 \mathrm{MW}$ and $2700 \mathrm{MW}$ separately.

Table 6. Cost comparison among various methodologies for System 2, $\mathrm{P}_{\mathrm{d}}=2700 \mathrm{MW}$.

\begin{tabular}{|c|c|c|c|c|c|c|c|c|c|c|c|}
\hline \multirow{2}{*}{$\begin{array}{l}\text { Unit } \\
\text { No. }\end{array}$} & \multirow{2}{*}{$\begin{array}{l}\text { Fuel } \\
\text { Used }\end{array}$} & \multicolumn{10}{|c|}{ Methods } \\
\hline & & IGA_MU & MSFLA & PSO & DE & RGA & NPSO-LRS & BSA & CSA-Cauchy & BAT & SDE \\
\hline $\mathrm{P} 1$ & 2 & 219.13 & 215.50 & 219.9962 & 218.2499 & 220.9376 & 223.33 & 218.58 & 218.1322 & 217.3232 & 218.593998 \\
\hline $\mathrm{P} 2$ & 1 & 211.16 & 210.72 & 212.7648 & 211.6626 & 212.6096 & 212.19 & 211.22 & 211.4116 & 209.9266 & 211.464175 \\
\hline P3 & 1 & 280.66 & 284.71 & 283.7391 & 280.7228 & 283.5811 & 276.21 & 279.56 & 281.6867 & 284.5552 & 280.657064 \\
\hline $\mathrm{P} 4$ & 3 & 238.48 & 239.77 & 240.5205 & 239.6315 & 240.0089 & 239.41 & 239.50 & 238.7456 & 237.2677 & 239.639428 \\
\hline P5 & 1 & 276.42 & 286.45 & 282.3127 & 278.4972 & 282.8920 & 274.64 & 279.97 & 279.8622 & 279.9804 & 279.934520 \\
\hline P6 & 3 & 240.47 & 240.18 & 240.5387 & 239.6315 & 240.4739 & 239.79 & 241.12 & 240.3328 & 240.1984 & 239.639428 \\
\hline P7 & 1 & 287.74 & 278.87 & 293.0846 & 288.5845 & 292.9792 & 285.53 & 289.80 & 287.7978 & 290.0943 & 287.727493 \\
\hline P8 & 3 & 240.76 & 242.06 & 240.2886 & 239.6315 & 240.1989 & 240.63 & 240.58 & 238.3435 & 238.3427 & 239.639428 \\
\hline P9 & 3 & 429.34 & 425.32 & 406.9797 & 428.5216 & 406.9988 & 429.26 & 426.89 & 427.8687 & 425.717 & 426.835856 \\
\hline P10 & 1 & 275.85 & 276.43 & 279.7752 & 274.8667 & 279.3199 & 278.65 & 272.80 & 275.8188 & 276.5845 & 275.868609 \\
\hline \multirow{2}{*}{\multicolumn{2}{|c|}{ Power Generated }} & 2700.00 & 2700.00 & 2700.00 & 2700.00 & 2700.00 & 2700.00 & 2700.00 & 2700.0 & 2700.00 & 2700.00 \\
\hline & & 624.52 & 624.12 & 624.5074 & 624.5146 & 624.5081 & 624.13 & 623.90 & 623.8566 & 623.8425 & 623.826575 \\
\hline
\end{tabular}

Table 7. Cost comparison among various methodologies for System 2, $\mathrm{P}_{\mathrm{d}}=2600 \mathrm{MW}$.

\begin{tabular}{cccccccccc}
\hline \multirow{2}{*}{ Unit No. } & \multirow{2}{*}{ Fuel Used } & \multicolumn{7}{c}{ Methods } \\
\cline { 2 - 9 } & & PSO & RGA & DE & MSFLA & GHS & BAT & SaDE & SDE \\
\hline P1 & 2 & - & - & - & 218.59 & 209.35 & 218.1376 & 219.99 & 216.539998 \\
P2 & 1 & - & - & - & 203.05 & 207.99 & 212.1547 & 212.76 & 210.721482 \\
P3 & 1 & - & - & - & 271.58 & 269.63 & 279.6484 & 283.74 & 278.640638 \\
P4 & 3 & - & - & - & 236.41 & 236.95 & 239.552 & 240.52 & 238.698832 \\
P5 & 1 & - & - & - & 276.43 & 265.48 & 271.4263 & 282.31 & 276.157152 \\
P6 & 3 & - & - & - & 241.92 & 235.88 & 237.2423 & 240.53 & 238.967574 \\
P7 & 1 & - & - & - & 287.73 & 273.51 & 287.7358 & 293.08 & 285.356480 \\
P8 & 3 & - & - & - & 240.85 & 237.76 & 236.4615 & 240.29 & 238.564461 \\
P9 & 1 & - & - & - & 344.20 & 403.33 & 339.8086 & 406.98 & 343.645968 \\
P10 & 1 & - & - & - & 279.23 & 260.11 & 277.8228 & 279.78 & 272.707417 \\
\hline Power Generated & 2600.002600 .002600 .002600 .00 & 2700.00 & 2600.00 & 2600.00 & 2600.00 \\
\multicolumn{2}{l}{ Total Cost } & 575.161575 .161575 .175 & 574.89 & 574.79 & 574.5609 & 574.54 & 574.387064 \\
\hline
\end{tabular}


Table 8. Cost comparison among various methodologies for System 2, $\mathrm{P}_{\mathrm{d}}=2500 \mathrm{MW}$.

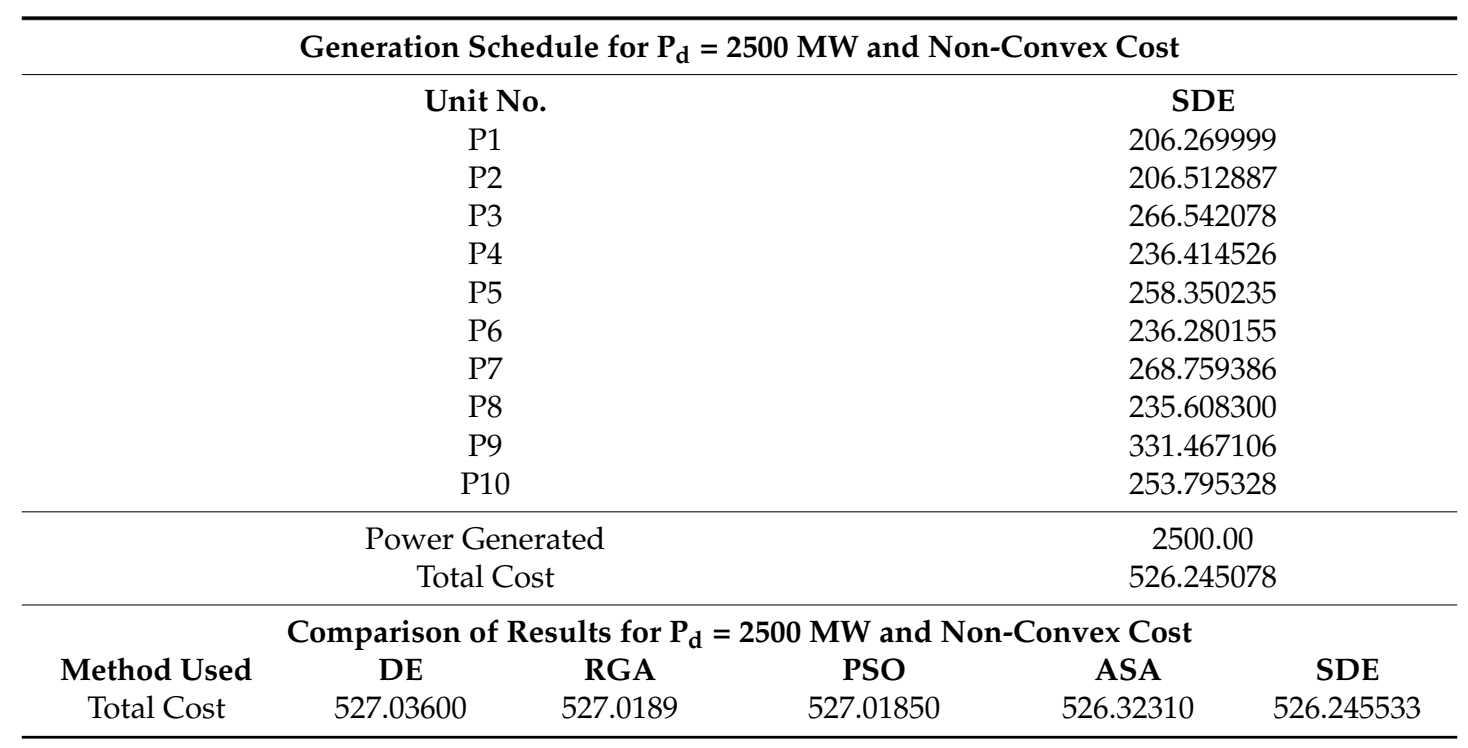

Table 9. Cost comparison among various methodologies for System 2, $\mathrm{P}_{\mathrm{d}}=2400 \mathrm{MW}$.

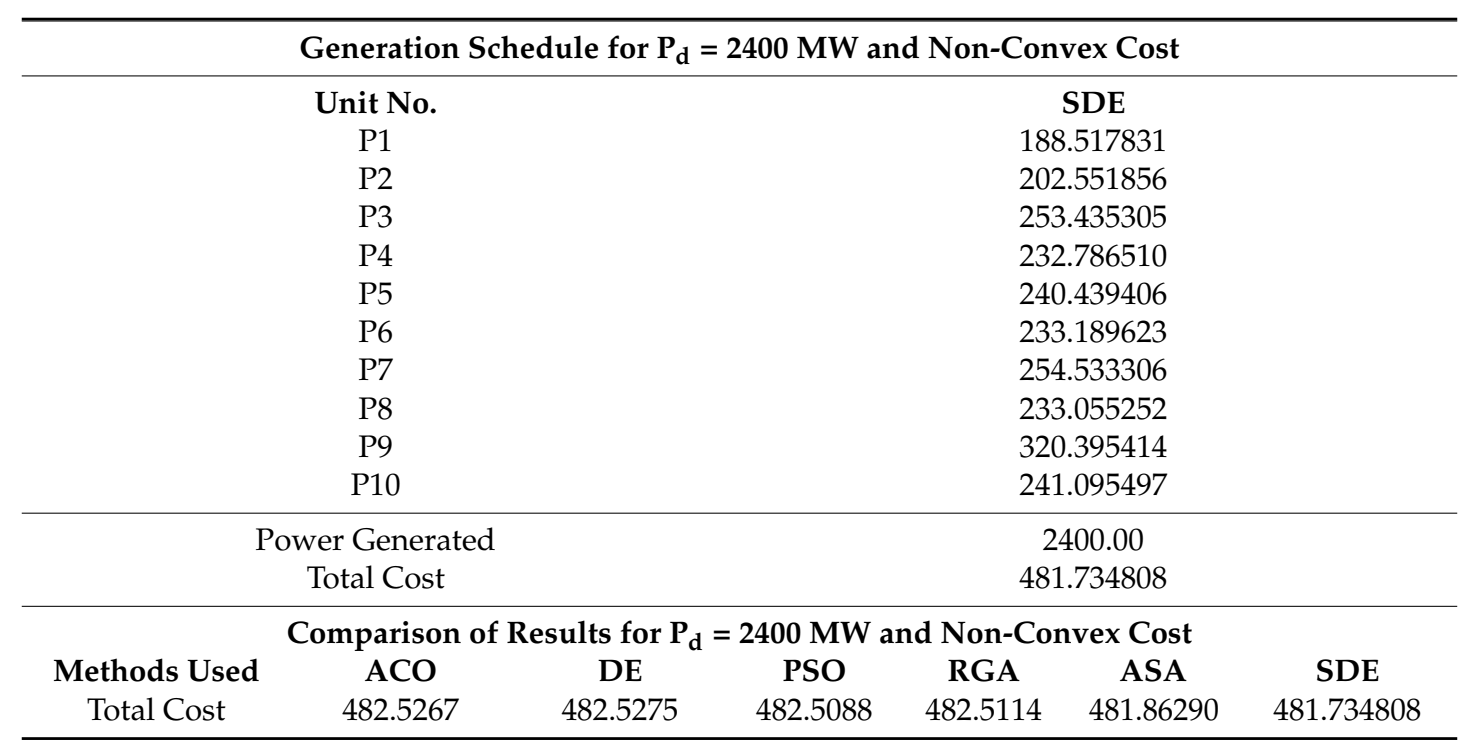

Table 10. Simulation results for various values of Crossover ratio.

\begin{tabular}{cccc}
\hline \multirow{2}{*}{ Power Demand (MW) } & \multicolumn{3}{c}{ Crossover Rate (CR) } \\
\cline { 2 - 4 } & $\mathbf{0 . 5}$ & $\mathbf{0 . 6}$ & $\mathbf{0 . 7}$ \\
\hline 2400 & 481.747921 & 481.734808 & 481.764849 \\
2500 & 526.253282 & 526.245533 & 526.277145 \\
2600 & 574.402910 & 574.387064 & 574.464175 \\
2700 & 623.832350 & 623.826575 & 623.843516 \\
\hline
\end{tabular}


Table 11. Comprehensive comparison of simulation results, standard deviation and computation time for system 2 (with valve point loading effects), $\mathrm{P}_{\mathrm{d}}=2700 \mathrm{MW}$.

\begin{tabular}{|c|c|c|c|c|c|}
\hline Methods & Min. Cost & Ave. Cost & Max. Cost & St. Deviation & CT (s) \\
\hline CGA-MU [28] & 624.7193 & 627.6087 & 633.8652 & NR & 25.65 \\
\hline IGA-MU [28] & 624.5178 & 625.8692 & 630.8705 & NR & 7.14 \\
\hline DE (a) [49] & 624.5146 & 624.5246 & 624.5458 & 0.0077 & 2.8236 \\
\hline RGA (a) [49] & 624.5081 & 624.5079 & 624.5088 & $2.9476 \times 10^{-5}$ & 4.1340 \\
\hline PSO (a) [49] & 624.5074 & 624.5074 & 624.5074 & $1.9691 \times 10^{-13}$ & 3.3852 \\
\hline GA [7] & 624.5050 & 624.7419 & 624.8169 & 0.1005 & 18.3 \\
\hline PSO_GM [29] & 624.3100 & 625.09 & 624.67 & 0.16 & NR \\
\hline TSA [7] & 624.3078 & 635.0623 & 624.8285 & 1.1593 & 9.71 \\
\hline PSO_LRS [27] & 624.2297 & 625.7887 & 628.3214 & NR & 0.93 \\
\hline CPSO [29] & 624.1700 & 624.78 & 624.55 & 0.13 & NR \\
\hline NPSO [27] & 624.1624 & 625.218 & 627.4237 & NR & 0.41 \\
\hline NPSO_LRS [27] & 624.1273 & 624.9985 & 626.9981 & NR & 1.08 \\
\hline MSFLA [40] & 624.11569 & 624.8958 & 628.3428 & NR & NR \\
\hline APSO [54] & 624.0145 & 624.8185 & 624.8185 & NR & 0.52 \\
\hline PSO (b) [30] & 624.0120 & 624.2055 & 624.4376 & 0.0889 & 0.308 \\
\hline CBPSO_RVM [29] & 623.9600 & 624.29 & 624.08 & 0.06 & NR \\
\hline $\mathrm{DE}(\mathrm{b})[30]$ & 623.9280 & 624.0068 & 624.0653 & 0.0271 & 0.625 \\
\hline BSA [51] & 623.9016 & 623.9757 & 624.0838 & NR & NR \\
\hline ACO [55] & 623.9000 & 624.3500 & 624.7800 & NR & 8.35 \\
\hline GA_G [56] & 623.8900 & 625.21 & 635.30 & NR & NR \\
\hline GA_MGC [56] & 623.8900 & 624.72 & 626.94 & NR & NR \\
\hline GA_C [56] & 623.8800 & 624.53 & 626.95 & NR & NR \\
\hline GA_BGC [56] & 623.8800 & 624.14 & 626.51 & NR & NR \\
\hline QPSO [30] & 623.8766 & 623.9639 & 624.4163 & 0.0688 & 0.315 \\
\hline DE_ALM [57] & 623.8716 & 626.1298 & 642.7812 & NR & 12.375 \\
\hline CSA [58] & 623.8684 & 623.9495 & 626.3666 & 0.2438 & 1.587 \\
\hline CSA_Cauchy [52] & 623.8566 & 624.1160 & 626.3440 & 0.7395 & 2.1 \\
\hline CSA_Gauss [52] & 623.8564 & 624.3618 & 626.3474 & 0.9826 & 2.2 \\
\hline GHS [40] & 623.84914 & 624.1341 & 625.3157 & NR & NR \\
\hline CQPSO [30] & 623.8476 & 623.8652 & 623.8885 & 0.0151 & 0.318 \\
\hline SFLA-GHS [40] & 623.84065 & 623.9521 & 624.7804 & NR & NR \\
\hline DSPSO_TSA [7] & 623.8375 & 623.8625 & 623.9001 & 0.0106 & 3.44 \\
\hline SQPSO [30] & 623.8319 & 623.8440 & 623.8605 & 0.0107 & 0.324 \\
\hline IODPSO_G [59] & 623.83 & 623.84 & 623.83 & 0.01 & NR \\
\hline IODPSO_L [59] & 623.83 & 623.83 & 623.83 & 0.00 & NR \\
\hline SADE_ALM [57] & 623.8278 & 624.7864 & 634.8313 & NR & 17.032 \\
\hline $\mathrm{SDE}$ & 623.826575 & 623.833894 & 623.8412 & $3.62 \times 10^{-3}$ & $\sim 10$ \\
\hline
\end{tabular}




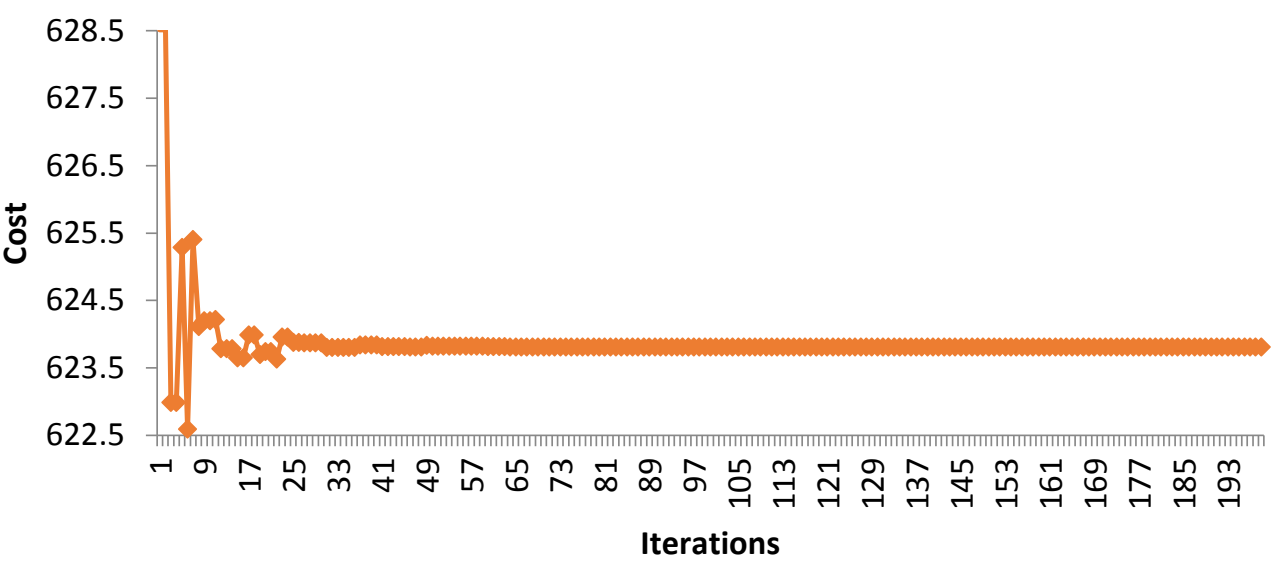

Figure 6. The convergence characteristics of the proposed for system 1 (without valve point loading effects), $\mathrm{P}_{\mathrm{d}}=2700 \mathrm{MW}$.

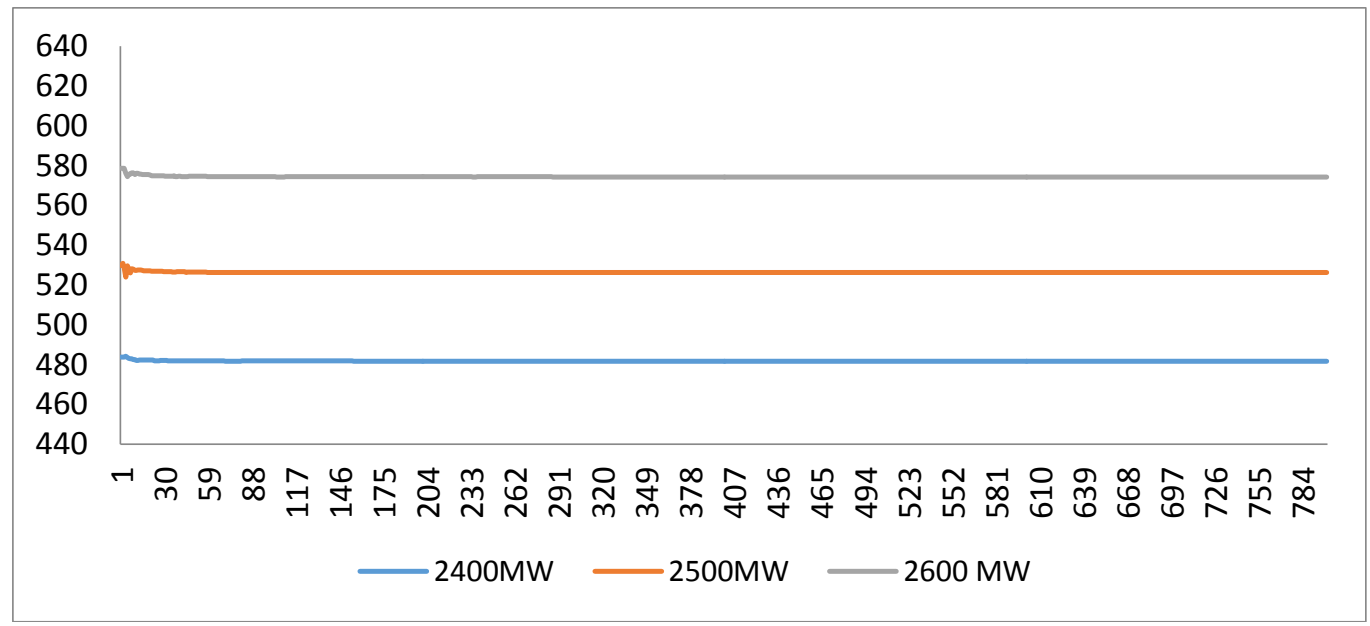

Figure 7. Convergence-characteristics of SBE algorithm for system 1 (without valve point loading effects), $P_{d}=2400 \mathrm{MW}, 2500 \mathrm{MW}, 2600 \mathrm{MW}$.

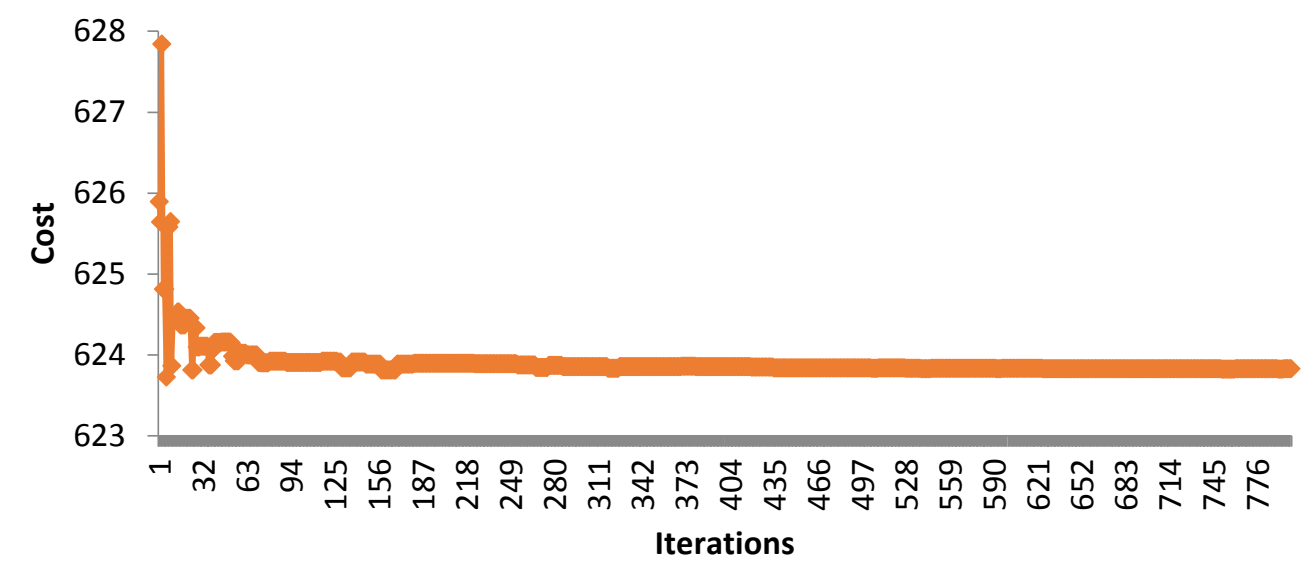

Figure 8. The convergence characteristics of the proposed for system 2 (with valve point loading effects), $P_{d}=2700 \mathrm{MW}$. 


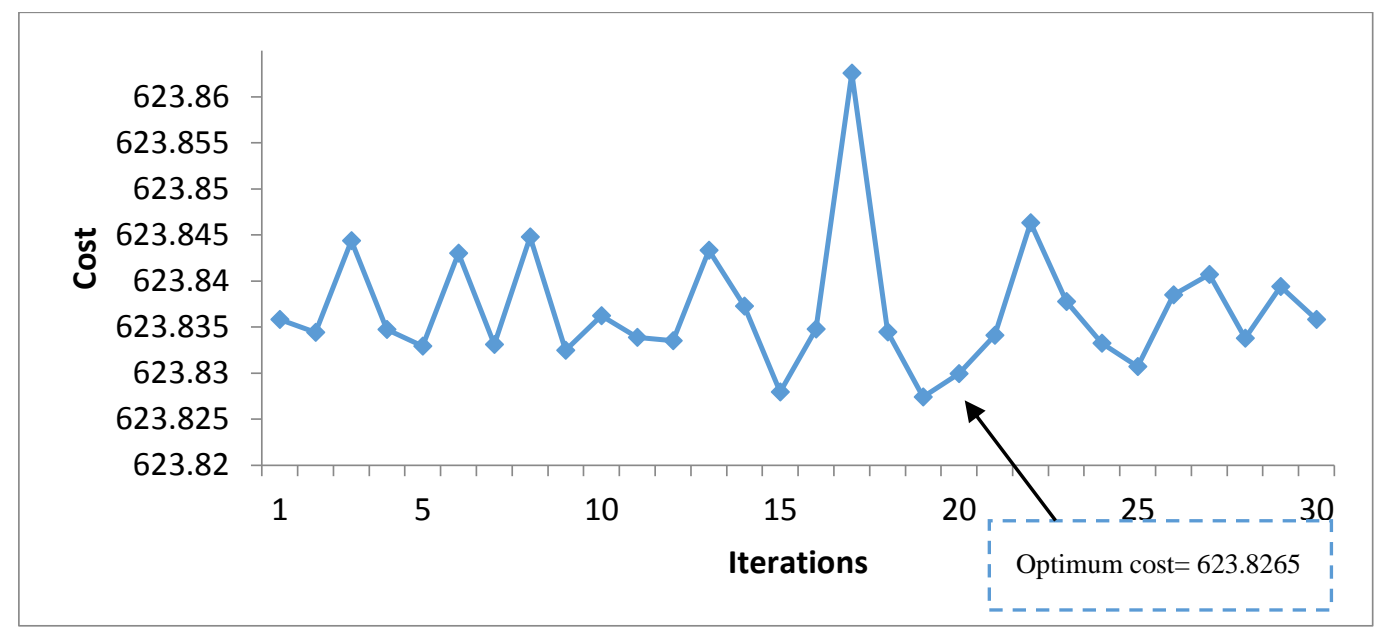

Figure 9. Cost-distribution around 30 run for system 2 (with valve point loading effects), $\mathrm{P}_{\mathrm{d}}=2700 \mathrm{MW}$.

Table 12. Summary of simulation results achieved by SDE for both convex and non-convex PED.

\begin{tabular}{|c|c|c|c|c|c|c|c|c|}
\hline \multirow{2}{*}{ Units } & \multicolumn{2}{|c|}{$P_{d}=2700 \mathrm{MW}$} & \multicolumn{2}{|c|}{$P_{d}=2600 \mathrm{MW}$} & \multicolumn{2}{|c|}{$P_{d}=2500 \mathrm{MW}$} & \multicolumn{2}{|c|}{$P_{d}=2400 \mathrm{MW}$} \\
\hline & Convex & Nonconvex & Convex & Nonconvex & Convex & Nonconvex & Convex & Nonconvex \\
\hline 1 & 218.249988 & 218.593998 & 216.544182 & 216.539998 & 206.519016 & 206.269999 & 189.740527 & 188.517831 \\
\hline 2 & 211.662614 & 211.464175 & 210.905752 & 210.721482 & 206.457317 & 206.512887 & 202.342694 & 202.551856 \\
\hline 3 & 280.722785 & 280.657064 & 278.544078 & 278.640638 & 265.739085 & 266.542078 & 253.895318 & 253.435305 \\
\hline 4 & 239.631553 & 239.639428 & 239.096668 & 238.698832 & 235.953146 & 236.414526 & 233.045560 & 232.786510 \\
\hline 5 & 278.497228 & 279.934520 & 275.519445 & 276.157152 & 258.017644 & 258.350235 & 241.829619 & 240.439406 \\
\hline 6 & 239.631562 & 239.639428 & 239.096668 & 238.967574 & 235.953163 & 236.280155 & 233.045548 & 233.189623 \\
\hline 7 & 288.584580 & 287.727493 & 285.717009 & 285.356480 & 268.863542 & 268.759386 & 253.275055 & 254.533306 \\
\hline 8 & 239.631491 & 239.639428 & 239.096669 & 238.564461 & 235.953149 & 235.608300 & 233.045563 & 233.055252 \\
\hline 9 & 428.521600 & 426.835856 & 343.493387 & 343.645968 & 331.487723 & 331.467106 & 320.383139 & 320.395414 \\
\hline 10 & 274.866600 & 275.868609 & 271.986142 & 272.707417 & 255.056214 & 253.795328 & 239.396978 & 241.095497 \\
\hline TP (MW) & 2700.00 & 2700.00 & 2600.00 & 2600.00 & 2500.00 & 2500.00 & 2400.00 & 2400.00 \\
\hline $\mathrm{TC}(\$ / \mathrm{h})$ & 623.809154 & 623.826575 & 574.380823 & 574.387064 & 526.238760 & 526.245533 & 481.722624 & 481.734808 \\
\hline
\end{tabular}

\section{Conclusions}

In this research, SDE was mapped in a $\mathrm{C}++$ programming environment and tested on standard test systems available in the literature. On the basis of the results achieved by computer implementation of the $\mathrm{C}++$ SDE application, it can be seen that SDE has a reduced generation cost and it can be concluded that the proposed algorithm can effectively and efficiently explore the solution space and that SDE is one of the promising optimization techniques.

Thus, the following conclusions can be made:

- $\quad$ SDE is a potential solution methodology for the PED problem, as it addresses the convex and non-convex PED equally.

- Results obtained from SDE are better in comparison with the current research available, which indicates the promise of the approach.

- $\quad$ SDE can easily be further modified and hybridized with other optimization techniques because it has fewer control parameters.

The presented research work has been entirely computer oriented and the main motivation was to develop a software application using $\mathrm{C}++$ based on SDE.

Author Contributions: The idea of the paper was conceived by N., S.S.H., S.A. and I.A.S. All of the listed authors designed the simulation and helped in coding and analyzed the data especially N., S.S.H. and corresponding author. The paper was written by all authors and was reviewed many times by all of them especially N., S.S.H., corresponding author, A.W., M.A., M.Y. and I.A. 
Acknowledgments: The authors would like to acknowledge Bahria University, Islamabad, Pakistan in providing all the help in carrying out the research work and funding it in terms of payment of Open Access Charges to this journal.

Conflicts of Interest: The authors declare no conflict of interest.

\section{Nomenclature}

$N$
$P_{G_{i}}$
$F_{i}\left(P_{G_{i}}\right)$
$P_{d}$
$P_{G_{i}}^{\min }$
$P_{G_{i}}^{\max }$
$P_{i k}^{\min }$
$P_{i k}^{\max }$
$F_{T}$
$a_{i k}, b_{i k}$ and $c_{i k}$
Optimization Techniques
AIS

AIS

APSO

ASA

BSA

CBPSO_RVM

CGA_MU

C-GRASP-DE

CPSO

CSA-Cauchy

CSA-Gauss

DEPSO

DSPSO_TSA

EALHN

GA_BGC

GA_C

GA_G

GA_MGC

GHS

HLN

HNN

IDE

IEP

IGA_MU

IODPSO_G

IODPSO_L

LI

MHNN

MPSO

MSFLA

NPSO

QPSO

RCGA

SADE_ALM

SDE

SFLA-GHS
Total no. of units

Power from $i$ th unit

Fuel cost associated with $i$ th unit

Total power demand

Minimum power generation from $i$ th unit

Maximum power generation from $i$ th unit

Minimum power generation from $i$ th unit consuming $k$ th fuel

Maximum power generation from $i$ th unit consuming $k$ th fuel

Total cost of power generation

Cost coefficients of the $i$ th generating unit consuming $k$ th fuel

Artificial Immune System

Adaptive particle swarm optimization

Adaptive Simulated Annealing

Back-tracking Search Algorithm

Combined particle swarm optimization with real-valued mutation

Conventional Genetic Algorithm with Multiplier Updating

Continuous Greedy Randomized Adaptive Search Procedure with Differential

Evolution

Combinatorial particle swarm optimization

Cuckoo Search Algorithm with Cauchy distribution

Cuckoo Search Algorithm with Gaussian distribution

Differential Evolution with Particle Swarm Optimization

Distributed Sobol Particle Swarm Optimization and Tabu Search Algorithm

Enhanced Augmented Lagrange Hopfield Network

Genetic Algorithm with best of Gaussian and Cauchy mutations

Genetic Algorithm GA with Cauchy mutation

Genetic Algorithm with Gaussian mutation

Genetic Algorithm with mean of Gaussian and Cauchy mutations

Global-best Harmony Search

Hopfield Lagrange Network

Hopfiled Neural Network

Improved Differential Evolution

Improved Evolutionary Programming

Improved Genetic Algorithm with Multiplier Updating

improved orthogonal design particle swarm optimization with global star structure improved orthogonal design particle swarm optimization with local ring structure Lamda-iteration

Modified Hopfield Neural Network

Modified Particle Swarm Optimization

Modified Shuffled Frog Leaping Algorithm

New particle swarm optimization

Quantum-behaved particle swarm optimization

Real-coded Genetic Algorithm

Self-adaptive Differential Evolution method with Augmented Lagrange Multiplier

Stud Differential Evolution

shuffled frog leaping algorithm with global-best harmony search algorithm 


\section{References}

1. Sayah, S.; Hamouda, A. A new hybrid heuristic algorithm for the nonconvex economic dispatch problem. In Proceedings of the 2017 5th International Conference on Electrical Engineering-Boumerdes (ICEE-B), Boumerdes, Algeria, 29-31 October 2017; pp. 1-6.

2. Wood, A.J.; Wollenberg, B.F. Power Generation, Operation, and Control; John Wiley \& Sons: Hoboken, NJ, USA, 2012.

3. Hindi, K.S.; Ab Ghani, M. Dynamic economic dispatch for large scale power systems: A lagrangian relaxation approach. Int. J. Electr. Power Energy Syst. 1991, 13, 51-56. [CrossRef]

4. Liang, Z.-X.; Glover, J.D. A zoom feature for a dynamic programming solution to economic dispatch including transmission losses. IEEE Trans. Power Syst. 1992, 7, 544-550. [CrossRef]

5. Papageorgiou, L.G.; Fraga, E.S. A mixed integer quadratic programming formulation for the economic dispatch of generators with prohibited operating zones. Electr. Power Syst. Res. 2007, 77, 1292-1296. [CrossRef]

6. Victoire, T.A.A.; Jeyakumar, A.E. Deterministically guided pso for dynamic dispatch considering valve-point effect. Electr. Power Syst. Res. 2005, 73, 313-322. [CrossRef]

7. Khamsawang, S.; Jiriwibhakorn, S. Dspso-tsa for economic dispatch problem with nonsmooth and noncontinuous cost functions. Energy Convers. Manag. 2010, 51, 365-375. [CrossRef]

8. Ab Ghani, M.R.; Hussein, S.T.; Ruddin, M.; Mohamad, M.; Jano, Z. An examination of economic dispatch using particle swarm optimization. MAGNT Res. Rep. 2015, 3, 193-209.

9. Duman, S.; Yorukeren, N.; Altas, I.H. A novel modified hybrid psogsa based on fuzzy logic for non-convex economic dispatch problem with valve-point effect. Int. J. Electr. Power Energy Syst. 2015, 64, 121-135. [CrossRef]

10. Júnior, J.d.A.B.; Nunes, M.V.A.; Nascimento, M.H.R.; Rodríguez, J.L.M.; Leite, J.C. Solution to economic emission load dispatch by simulated annealing: Case study. Electr. Eng. 2017, 1-13. [CrossRef]

11. Lin, W.-M.; Cheng, F.-S.; Tsay, M.-T. An improved tabu search for economic dispatch with multiple minima. IEEE Trans. Power Syst. 2002, 17, 108-112. [CrossRef]

12. Aydin, D.; Yavuz, G.; Özyön, S.; Yaşar, C.; Stützle, T. Artificial Bee colony framework to non-convex economic dispatch problem with valve point effects: A case study. In Proceedings of the Genetic and Evolutionary Computation Conference Companion, Berlin, Germany, 15-19 July 2017; pp. 1311-1318.

13. Mouassa, S.; Bouktir, T. Artificial bee colony algorithm for solving economic dispatch problems with non-convex cost functions. Int. J. Power Energy Convers. 2017, 8, 146-165. [CrossRef]

14. Karthik, N.; Parvathy, A.; Arul, R. Non-convex economic load dispatch using cuckoo search algorithm. Indones. J. Electr. Eng. Comput. Sci. 2017, 5, 48-57. [CrossRef]

15. Souza, R.O.G.; Oliveira, E.S.; Junior, I.C.S.; Marcato, A.L.M.; de Olveira, M.T. Flower pollination algorithm applied to the economic dispatch problem with multiple fuels and valve point effect. In Proceedings of the Portuguese Conference on Artificial Intelligence, Porto, Portugal, 5-8 September 2017; pp. 260-270.

16. Bhattacharya, S.; Kuanr, B.R.; Routray, A.; Dash, A. Implementation of bat algorithm in economic dispatch for units with multiple fuels and valve-point effect, Electrical. In Proceedings of the 2017 IEEE International Conference on Instrumentation and Communication Engineering (ICEICE), Karur, India, 27-28 April 2017; pp. 1-7.

17. Kheshti, M.; Kang, X.; Bie, Z.; Jiao, Z.; Wang, X. An effective lightning flash algorithm solution to large scale non-convex economic dispatch with valve-point and multiple fuel options on generation units. Energy 2017, 129, 1-15. [CrossRef]

18. Kamboj, V.K.; Bhadoria, A.; Bath, S. Solution of non-convex economic load dispatch problem for small-scale power systems using ant lion optimizer. Neural Comput. Appl. 2017, 28, 2181-2192. [CrossRef]

19. Cui, S.; Wang, Y.-W.; Lin, X.; Liu, X.-K. Distributed auction optimization algorithm for the nonconvex economic dispatch problem based on the gossip communication mechanism. Int. J. Electr. Power Energy Syst. 2018, 95, 417-426. [CrossRef]

20. Bentouati, B.; Chaib, L.; Chettih, S.; Wang, G.-G. An efficient stud krill herd framework for solving non-convex economic dispatch problem. World Acad. Sci. Eng. Technol. Int. J. Electr. Comput. Energ. Electron. Commun. Eng. 2017, 11, 1095-1100. 
21. Das, D.; Bhattacharya, A.; Ray, R. Symbiotic organisms search algorithm for economic dispatch problems. In Proceedings of the 2017 Second International Conference on Electrical, Computer and Communication Technologies (ICECCT), Coimbatore, India, 22-24 February 2017; pp. 1-7.

22. Dihem, A.; Salhi, A.; Naimi, D.; Bensalem, A. Solving smooth and non-smooth economic dispatch using water cycle algorithm. In Proceedings of the 2017 5th International Conference on Electrical Engineering-Boumerdes (ICEE-B), Boumerdes, Algeria, 29-31 October 2017; pp. 1-6.

23. Pham, L.H.; Nguyen, T.T.; Vo, D.N.; Tran, C.D. Adaptive cuckoo search algorithm based method for economic load dispatch with multiple fuel options and valve point effect. Int. J. Hybrid Inf. Technol. 2016, 9, 41-50. [CrossRef]

24. Lee, S.-C.; Kim, Y.-H. An enhanced lagrangian neural network for the eld problems with piecewise quadratic cost functions and nonlinear constraints. Electr. Power Syst. Res. 2002, 60, 167-177. [CrossRef]

25. Secui, D.C. A modified symbiotic organisms search algorithm for large scale economic dispatch problem with valve-point effects. Energy 2016, 113, 366-384. [CrossRef]

26. Adarsh, B.; Raghunathan, T.; Jayabarathi, T.; Yang, X.-S. Economic dispatch using chaotic bat algorithm. Energy 2016, 96, 666-675. [CrossRef]

27. Selvakumar, A.I.; Thanushkodi, K. A new particle swarm optimization solution to nonconvex economic dispatch problems. IEEE Trans. Power Syst. 2007, 22, 42-51. [CrossRef]

28. Chiang, C.-L. Improved genetic algorithm for power economic dispatch of units with valve-point effects and multiple fuels. IEEE Trans. Power Syst. 2005, 20, 1690-1699. [CrossRef]

29. Lu, H.; Sriyanyong, P.; Song, Y.H.; Dillon, T. Experimental study of a new hybrid pso with mutation for economic dispatch with non-smooth cost function. Int. J. Electr. Power Energy Syst. 2010, 32, 921-935. [CrossRef]

30. Niu, Q.; Zhou, Z.; Zhang, H.-Y.; Deng, J. An improved quantum-behaved particle swarm optimization method for economic dispatch problems with multiple fuel options and valve-points effects. Energies 2012, 5, 3655-3673. [CrossRef]

31. Storn, R.; Price, K. Differential evolution-A simple and efficient heuristic for global optimization over continuous spaces. J. Glob. Optim. 1997, 11, 341-359. [CrossRef]

32. Balamurugan, R.; Subramanian, S. Self-adaptive differential evolution based power economic dispatch of generators with valve-point effects and multiple fuel options. Fuel 2007, 1, 543-550.

33. Surekha, P.; Sumathi, S. An improved differential evolution algorithm for optimal load dispatch in power systems including transmission losses. IU-J. Electr. Electron. Eng. 2011, 11, 1379-1390.

34. Reddy, A.S.; Vaisakh, K. Shuffled differential evolution for economic dispatch with valve point loading effects. Int. J. Electr. Power Energy Syst. 2013, 46, 342-352. [CrossRef]

35. Neto, J.X.V.; Reynoso-Meza, G.; Ruppel, T.H.; Mariani, V.C.; dos Santos Coelho, L. Solving non-smooth economic dispatch by a new combination of continuous grasp algorithm and differential evolution. Int. J. Electr. Power Energy Syst. 2017, 84, 13-24. [CrossRef]

36. Khatib, W.; Fleming, P.J. The Stud GA: A Mini Revolution? In Proceedings of the International Conference on Parallel Problem Solving from Nature, Amsterdam, The Netherlands, 27-30 September 1998; pp. 683-691.

37. Wang, G.-G.; Gandomi, A.H.; Alavi, A.H. Stud krill herd algorithm. Neurocomputing 2014, 128, 363-370. [CrossRef]

38. Haroon, S.S.; Malik, T.N. Environmental economic dispatch of hydrothermal energy system using stud differential evolution. In Proceedings of the 2016 IEEE 16th International Conference on Environment and Electrical Engineering (EEEIC), Florence, Italy, 7-10 June 2016; pp. 1-5.

39. Abouheaf, M.I.; Lee, W.-J.; Lewis, F.L. Dynamic formulation and approximation methods to solve economic dispatch problems. IET Gener. Transm. Distrib. 2013, 7, 866-873. [CrossRef]

40. Vaisakh, K.; Reddy, A.S. Msfla/ghs/sfla-ghs/sde algorithms for economic dispatch problem considering multiple fuels and valve point loadings. Appl. Soft Comput. 2013, 13, 4281-4291. [CrossRef]

41. Park, J.; Kim, Y.; Eom, I.; Lee, K. Economic load dispatch for piecewise quadratic cost function using hopfield neural network. IEEE Trans. Power Syst. 1993, 8, 1030-1038. [CrossRef]

42. Park, Y.-M.; Won, J.-R.; Park, J.-B. A new approach to economic load dispatch based on improved evolutionary programming. Eng. Intell. Syst. Electr. Eng. Commun. 1998, 6, 103-110.

43. Thang, N.T. Economic emission load dispatch with multiple fuel options using hopfiled lagrange network. Int. J. Adv. Sci. Technol. 2013, 57, 9-24. 
44. Park, J.-B.; Lee, K.-S.; Shin, J.-R.; Lee, K.Y. A particle swarm optimization for economic dispatch with nonsmooth cost functions. IEEE Trans. Power Syst. 2005, 20, 34-42. [CrossRef]

45. Dieu, V.N.; Ongsakul, W. Economic dispatch with multiple fuel types by enhanced augmented lagrange hopfield network. Appl. Energy 2012, 91, 281-289.

46. Panigrahi, B.; Yadav, S.R.; Agrawal, S.; Tiwari, M. A clonal algorithm to solve economic load dispatch. Electr. Power Syst. Res. 2007, 77, 1381-1389. [CrossRef]

47. Baskar, S.; Subbaraj, P.; Rao, M. Hybrid real coded genetic algorithm solution to economic dispatch problem. Comput. Electr. Eng. 2003, 29, 407-419. [CrossRef]

48. Noman, N.; Iba, H. Differential evolution for economic load dispatch problems. Electr. Power Syst. Res. 2008, 78, 1322-1331. [CrossRef]

49. Manoharan, P.; Kannan, P.; Baskar, S.; Iruthayarajan, M. Penalty parameter-less constraint handling scheme based evolutionary algorithm solutions to economic dispatch. IET Gener. Transm. Distrib. 2008, 2, 478-490. [CrossRef]

50. Mathur, D. Biogeography based optimization of different economic dispatch problems. IEEE Trans. Power Syst. 2010, 25, 1064-1077.

51. Modiri-Delshad, M.; Kaboli, S.H.A.; Taslimi-Renani, E.; Rahim, N.A. Backtracking search algorithm for solving economic dispatch problems with valve-point effects and multiple fuel options. Energy 2016, 116, 637-649. [CrossRef]

52. Tran, C.D.; Dao, T.T.; Vo, V.S.; Nguyen, T.T. Economic load dispatch with multiple fuel options and valve point effect using cuckoo search algorithm with different distributions. Int. J. Hybrid Inf. Technol. 2015, 8, 305-316. [CrossRef]

53. Santhi, R.; Subramanian, S. Adaptive sa for economic dispatch with multiple fuel options. J. Comput. Sci. Eng. 2011, 6, 17-24.

54. Selvakumar, A.I.; Thanushkodi, K. Anti-predatory particle swarm optimization: Solution to nonconvex economic dispatch problems. Electr. Power Syst. Res. 2008, 78, 2-10. [CrossRef]

55. Pothiya, S.; Ngamroo, I.; Kongprawechnon, W. Ant colony optimisation for economic dispatch problem with non-smooth cost functions. Int. J. Electr. Power Energy Syst. 2010, 32, 478-487. [CrossRef]

56. Binetti, G.; Naso, D.; Turchiano, B. Genetic algorithm based on the lagrange method for the non-convex economic dispatch problem. In Proceedings of the 2015 IEEE 20th Conference on Emerging Technologies \& Factory Automation (ETFA), Luxembourg, Luxembourg, 8-11 September 2015; pp. 1-7.

57. Thitithamrongchai, C.; Eua-Arporn, B. Hybrid self-adaptive differential evolution method with augmented lagrange multiplier for power economic dispatch of units with valve-point effects and multiple fuels. In Proceedings of the 2006 IEEE PES Power Systems Conference and Exposition, Atlanta, GA, USA, 29 October-1 November 2006; pp. 908-914.

58. Vo, D.N.; Schegner, P.; Ongsakul, W. Cuckoo search algorithm for non-convex economic dispatch. IET Gener. Transm. Distrib. 2013, 7, 645-654. [CrossRef]

59. Qin, Q.; Cheng, S.; Chu, X.; Lei, X.; Shi, Y. Solving non-convex/non-smooth economic load dispatch problems via an enhanced particle swarm optimization. Appl. Soft Comput. 2017, 59, 229-242. [CrossRef]

(C) 2018 by the authors. Licensee MDPI, Basel, Switzerland. This article is an open access article distributed under the terms and conditions of the Creative Commons Attribution (CC BY) license (http:/ / creativecommons.org/licenses/by/4.0/). 